\title{
On Laminar to Turbulent Transition of Arc-Jet Flow in the NASA Ames Panel Test Facility
}

\author{
Tahir Gökçen* and Antonella I. Alunni ${ }^{\dagger}$ \\ ERC, Inc., NASA Ames Research Center, Moffett Field, CA 94035
}

This paper provides experimental evidence and supporting computational analysis to characterize the laminar to turbulent flow transition in a high enthalpy arc-jet facility at NASA Ames Research Center. The arc-jet test data obtained in the $20 \mathrm{MW}$ Panel Test Facility include measurements of surface pressure and heat flux on a water-cooled calibration plate, and measurements of surface temperature on a reaction-cured glass coated tile plate. Computational fluid dynamics simulations are performed to characterize the arc-jet test environment and estimate its parameters consistent with the facility and calibration measurements. The present analysis comprises simulations of the nonequilibrium flowfield in the facility nozzle, test box, and flowfield over test articles. Both laminar and turbulent simulations are performed, and the computed results are compared with the experimental measurements, including Stanton number dependence on Reynolds number. Comparisons of computed and measured surface heat fluxes (and temperatures), along with the accompanying analysis, confirm that that the boundary layer in the Panel Test Facility flow is transitional at certain archeater conditions.

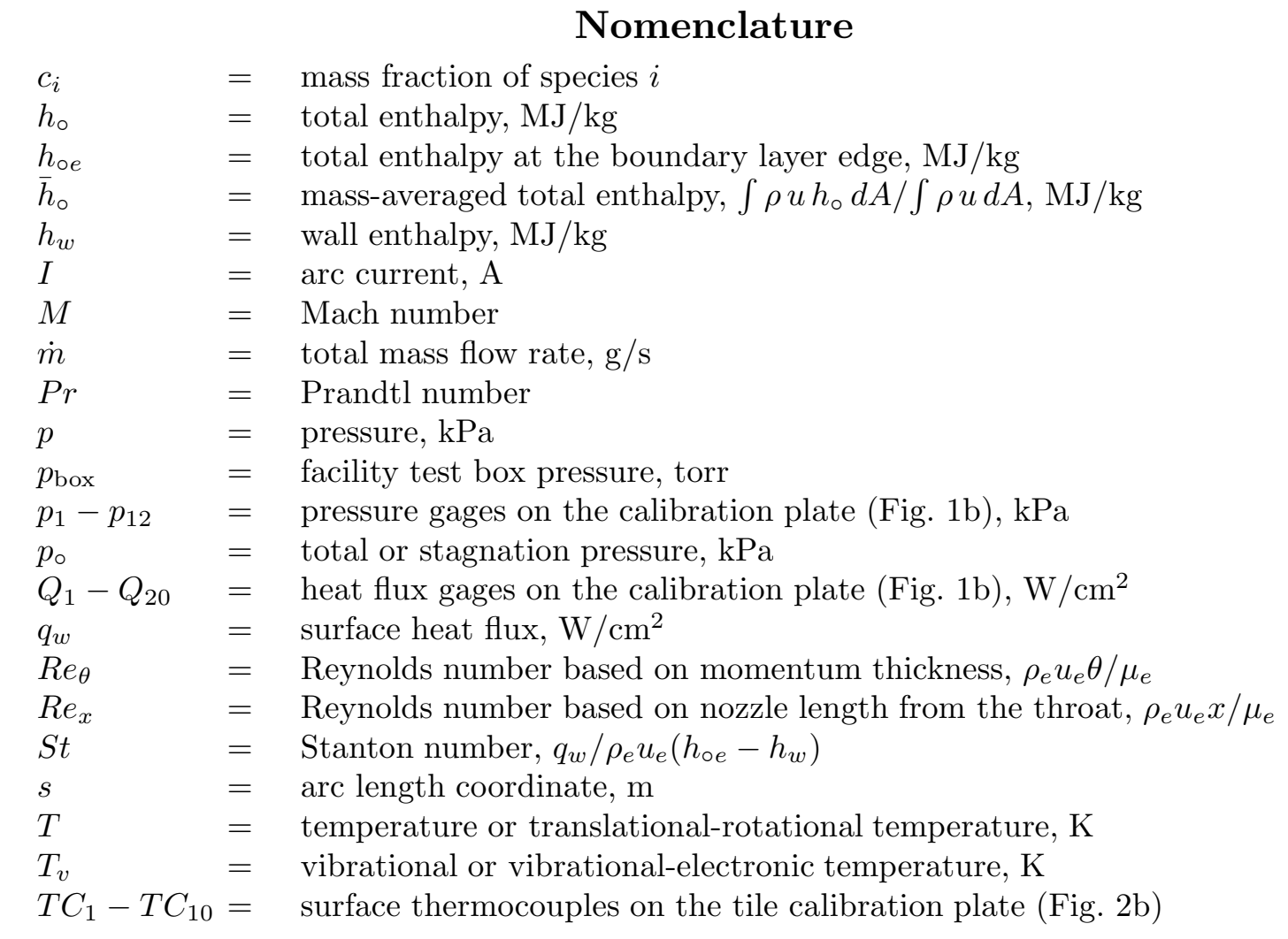

* MS 230-2, Senior Research Scientist, Associate Fellow AIAA

$\dagger$ MS 234-1, Research Scientist, Member AIAA 


$\begin{array}{ll}u_{e} & =\text { tangential component of velocity at the boundary layer edge, } \mathrm{m} / \mathrm{s} \\ V & =\text { arc voltage, } \mathrm{V} \\ \epsilon & =\text { hemispherical emissivity } \\ \rho_{e} & =\text { density at the boundary layer edge, } \mathrm{kg} / \mathrm{m}^{3} \\ \mu_{e} & =\text { mixture viscosity at the boundary layer edge, Pa.s } \\ \theta & =\text { boundary layer momentum thickness, } \mathrm{cm}\end{array}$

\section{Introduction}

Arc-jet facilities provide the primary means to study the performance of various types of thermal protection systems (TPS) used on the outer surfaces of spacecraft in an aerothermodynamic heating environment. Characterization of the arc-jet test flow and its parameters is critically important for evaluation of any TPS performance. Computational fluid dynamics (CFD)-based analysis has become an integral part of arc-jet testing, and arc-jet test flow characterization is usually achieved through CFD computations combined with facility and calibration measurements.

Analysis of recent tests in the NASA Ames 20 MW Panel Test Facility (PTF) reported in Ref. 1 concluded that the boundary layer flow in the PTF is transitional at the test conditions of interest, based on comparisons of computed laminar and turbulent simulation results with the water-cooled calibration plate data. Also, the historical PTF database had indicated the presence of transitional to turbulent flow, primarily because the measured heat fluxes were generally higher than the laminar predictions or theory. ${ }^{2-4}$

In order to investigate transition to turbulence in the PTF flow, a water-cooled calibration plate with surface pressure and heat flux gages and a tile plate coated with reaction-cured-glass (RCG) and instrumented with surface thermocouples were tested. These tests were run at a constant arc-heater current and varying mass flow rates (or arc-heater pressures). At lower mass flow rates or lower archeater pressures, the flow is expected to be laminar. With increasing mass flow rate and pressure, possible transition from laminar to turbulent flow, if it occurs, can be inferred from the two calibration plate measurements. Since keeping the arc current constant yields a relatively narrow range for total enthalpy, any substantial increase in the measured heat flux on the water-cooled plate and/or in the measured surface temperature of the RCG tile plate is considered to be an indication of transition from laminar to turbulent flow. The objective of the present paper is to provide experimental evidence and supporting computational analysis to confirm the laminar to turbulent flow transition in the PTF. The present analysis comprises computational Navier-Stokes simulations of the nonequilibrium flowfield in the facility nozzle and test box as well as the flowfield over the models, and comparisons with the experimental measurements. Both laminar and turbulent flow simulation results are presented. Comparisons of the CFD results, test data and flat plate boundary layer theory are also made in terms of Stanton number dependence on Reynolds number.

\section{Arc-Jet Facility and Tests}

NASA Ames Research Center (ARC) has a number of arc-jet facilities within its Arc-Jet Complex that have long been used in development and testing of thermal protection systems for entry vehicles such as the Space Shuttle Orbiter and planetary probes. ${ }^{5-8}$ Of these facilities, the PTF consists of a constricted arc heater, a 20-MW DC power supply, a semi-elliptical nozzle, a test chamber, and supplementary systems including steam ejector vacuum system, cooling-water system and data acquisition system. The PTF is designed to operate at total pressures of 1-9 atm and total enthalpies of 7-35 MJ/kg (air). ${ }^{7}$

The PTF semi-elliptical nozzle is a converging-diverging nozzle. The converging section starts from a circular shape at the inlet and transitions into a semi-elliptical shape at the throat (one-half of an ellipse, with the major axis forming the bottom portion of the nozzle). The diverging section, preserving a semi-elliptical shape, expands conically from the throat to the test section. The nozzle length from the throat is $1.501 \mathrm{~m}$, and the semi-ellipse parameters $(2 a \times b)$ for the nozzle throat and exit cross sections are $7.18 \mathrm{~cm} \times 1.80 \mathrm{~cm}$ and $43.18 \mathrm{~cm} \times 10.80 \mathrm{~cm}$, respectively. The bottom surface of the nozzle 




a)

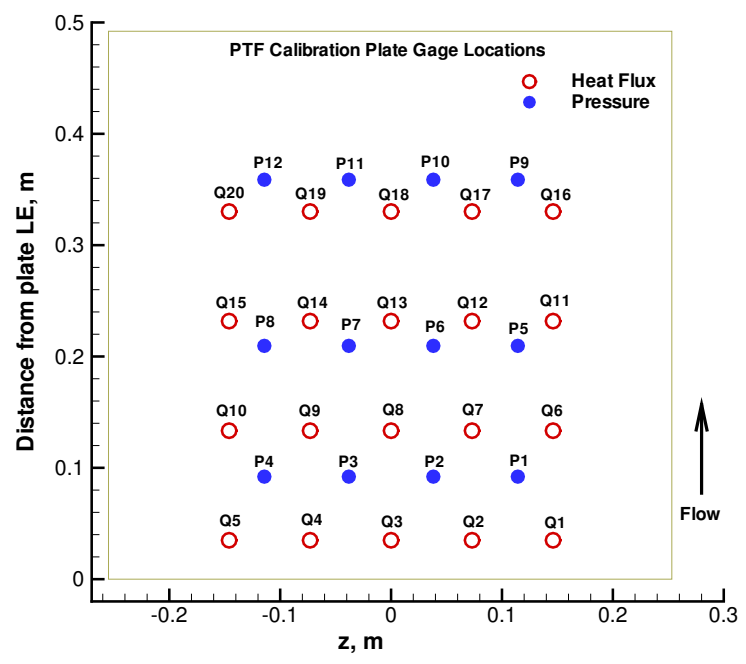

b)

Fig. 1 PTF cold-wall calibration plate test: a) a photograph of the water-cooled calibration plate; and b) locations of twenty heat flux gages and twelve pressure transducers.

includes a high-density ceramic (silfrax) boundary-layer conditioning plate for the last $25.4 \mathrm{~cm}$ of the nozzle, which provides a hot-wall condition and boundary layer profile more typical of flight. Except for the conditioning plate, all of the nozzle walls are water-cooled. Test articles (usually flat panels) are mounted flush to the bottom surface of the nozzle in a supersonic jet at the nozzle exit (see Refs. 6-7 for details). The test plate can be deflected from $-5^{\circ}$ to $+9^{\circ}$ with respect to the nozzle bottom surface plane. Positive plate deflection creates a compression ramp at the nozzle exit, resulting in increased surface pressure and heating rates on the test plate. Conversely, negative plate deflection creates a flow expansion at the nozzle exit, reducing pressure and heating rates on the plate surface. In the PTF, arc-jet heating conditions are usually calibrated using a water-cooled calibration plate. Figure 1a shows a photograph of the water-cooled calibration plate attached to the semi-elliptical nozzle bottom surface, with the heat flux calorimeter and pressure gage locations on the plate indicated in Fig. 1b.

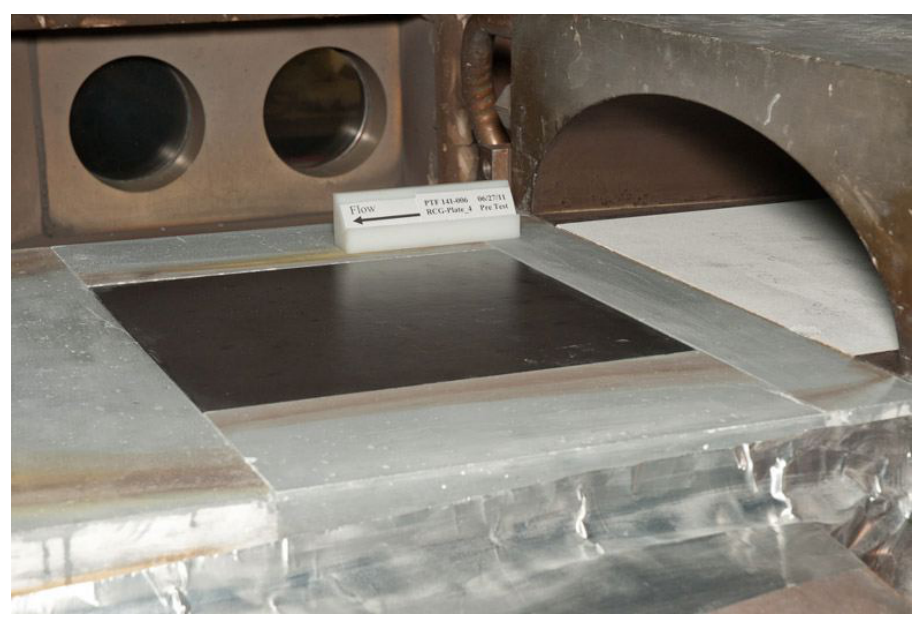

a)



b)

Fig. 2 PTF hot-wall calibration plate test: a) a photograph of the RCG-coated tile plate; and $b$ ) locations of six thermocouples on the tile plate.

In addition to the water-cooled calibration plate, an LI-2200 tile plate coated with reaction-cured- 
glass (RCG) and instrumented with surface thermocouples was tested in the present test series (PTF Cal Run 135 and PTF 141). A pretest photograph of the RCG-coated tile plate is shown in Fig. 2a. Note that the flow direction is right to left, and the plate is deflected to a prescribed angle during the test. The RCG tile plate had six Type R surface thermocouples, and locations of the thermocouples are shown in Fig. 2b. In addition to the thermocouple data, the tile model surface temperatures were also measured using one-color (Mikron M190H: 0.78-1.06 $\mu \mathrm{m}$ ) and two-color (Mikron M190 R2: 0.78-1.06 $\mu \mathrm{m}$ and 0.9-1.06 $\mu \mathrm{m}$ ) pyrometers as well as an infrared camera (Mikron M9200).

\section{Computational Approach}

The Data Parallel Line Relaxation (DPLR) $\operatorname{code}^{9,10}$ is used for computations of the nonequilibrium flow in the PTF nozzle, test box, and flowfield over test articles. DPLR has been used extensively at Ames for hypersonic flight, planetary entry and arc-jet simulations, and its results have been compared favorably against a wide variety of flight and ground-based experiments. DPLR provides various options for thermophysical models and formulation. For CFD calculations presented in this paper, threedimensional Navier-Stokes equations, supplemented with the equations accounting for nonequilibrium kinetic processes, are used in the formulation. The thermochemical model employed for the arc-jet flow includes six species $\left(\mathrm{N}_{2}, \mathrm{O}_{2}, \mathrm{NO}, \mathrm{N}, \mathrm{O}, \mathrm{Ar}\right)$, and the thermal state of the gas is described by two temperatures within the framework of Park's two-temperature model. ${ }^{11,12}$ In the two-temperature model, excitations of internal degrees of freedom are divided into two classes, and it is assumed that excitations are equilibrated within each class. The translational and rotational modes of energy make up one class, and it is characterized by a translational-rotational temperature, $T$. The vibrational and electronic modes form the other class, and it is characterized by a vibrational-electronic temperature, $T_{v}$.

The flowfield in an arc-jet facility, from the arc heater to the test section, is a very complex, three-dimensional flow with various nonequilibrium processes occurring. In order to simulate the flowfield, several simplifying assumptions are made, and corresponding numerical boundary conditions are prescribed for CFD simulations. The approach taken here follows that of Ref. 1., in which the CFD boundary conditions are set such that the computations reproduce the facility and calibration data as well as possible. The facility data include measurements of total pressure (arc-heater pressure), mass flow rate, total bulk enthalpy, and test box pressure, while the calibration plate data include surface heat flux and pressure measurements. For surface recombination reactions on the RCG-coated tile plates, catalytic efficiency expressions developed by Stewart ${ }^{13}$ are prescribed. Both laminar and turbulent flow simulations are performed. The turbulent simulations employ the Shear Stress Transport (SST) model of Menter. ${ }^{14,15}$ The computational grids for all CFD simulations presented in this paper are generated using a commercial software package, Gridgen. ${ }^{16}$ Further details of the computational approach can be found in Ref. 1.

As an illustration of a typical flowfield simulation, Fig. 3 shows computed Mach number contours of the PTF nozzle flow with a test plate at zero deflection angle. In Fig. 3a, the Mach number contours are shown on the x-y plane of the nozzle/test box flowfield (symmetry plane) and on four y-z planes: one at the nozzle inlet, one at the nozzle throat, one at the conditioning plate, and another at the nozzle exit. The panel test article is located on the $\mathrm{x}-\mathrm{z}$ plane downstream of the nozzle exit; the leading edge of the panel is at the nozzle exit plane. The predicted frozen Mach number at the nozzle exit is 4.2. Due to the nonequilibrium expansion process in arc-jet nozzles, the chemical composition freezes near the throat where the flow is dissociated and vibrationally excited. As shown in Fig. 3b, the computations also predict that the flow is chemically frozen and in vibrational nonequilibrium before it reaches the nozzle exit. Note that oxygen remains fully dissociated within the entire flowfield except in the boundary layer near the walls, while nitrogen is partially dissociated. Also note that the expansion waves emanating from the corner of the nozzle exit connected to the test box are clearly observed in the computed Mach number contours. The interaction of the expansion waves with the on-coming flow over the plate affects and ultimately determines the useful test area in this semi-free jet test configuration. 


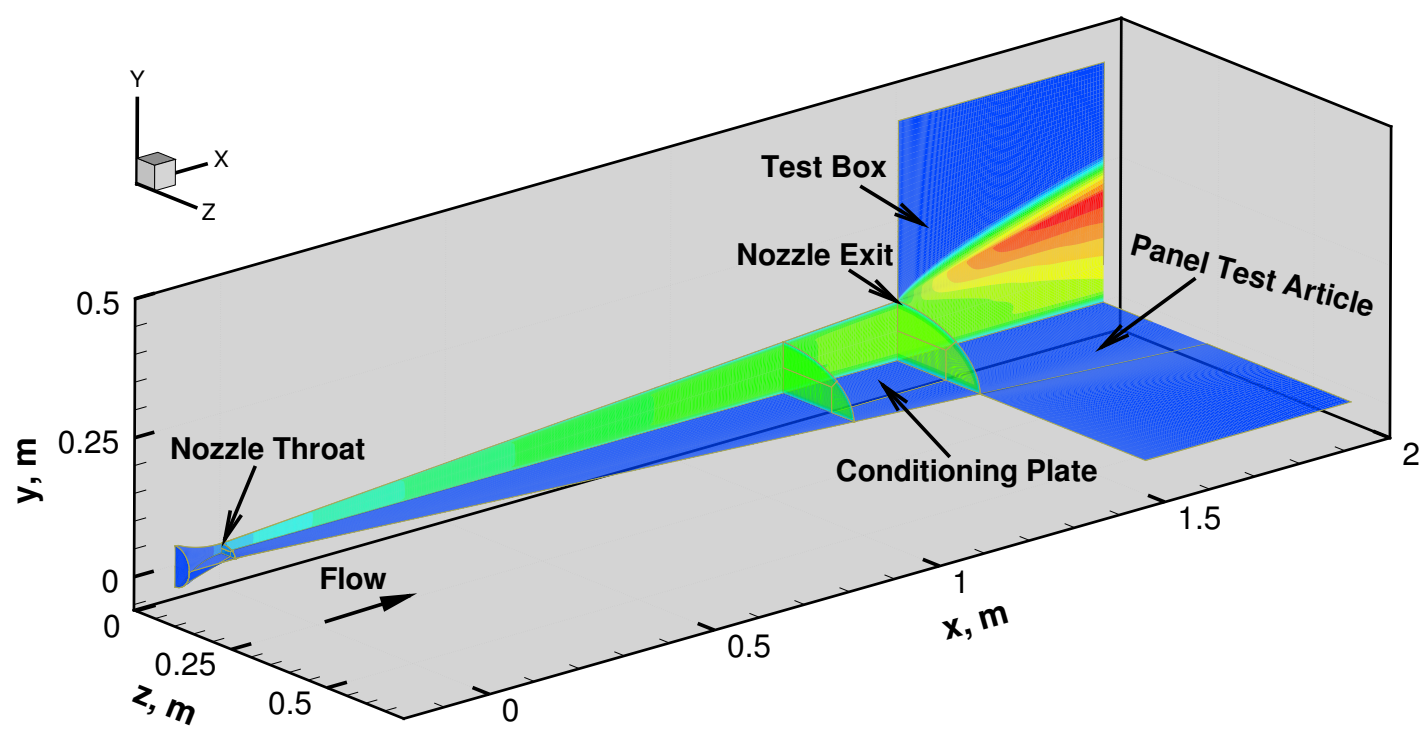

a) Mach number contours
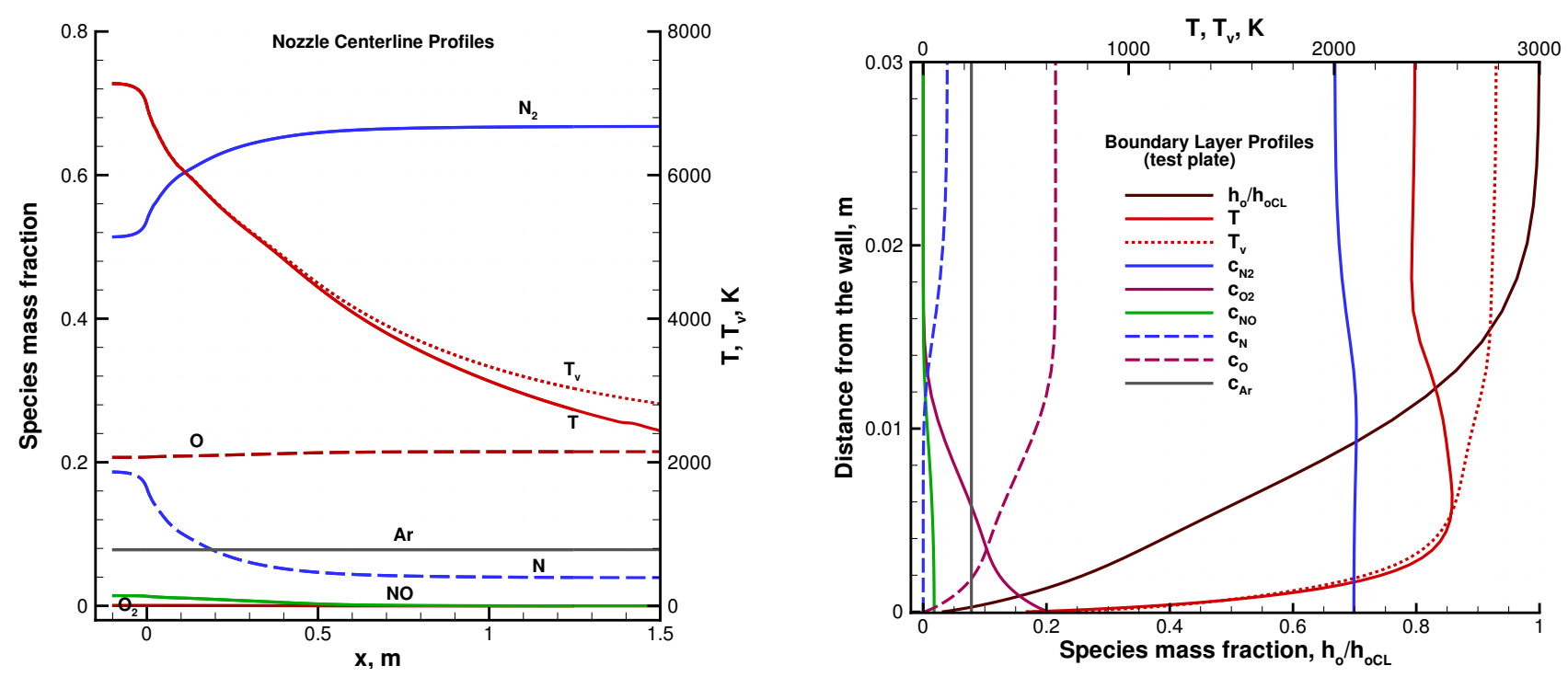

b) Flow properties along the nozzle centerline and in the boundary layer over the test plate at $x=1.542 \mathrm{~m}$

Fig. 3 Computed PTF nozzle flow and flowfield over the calibration plate at $0^{\circ}$ deflection. $p_{o}=933 \mathrm{kPa}, h_{o}=\bar{h}_{\circ}=18.7 \mathrm{MJ} / \mathrm{kg}, p_{\text {box }}=2$ torr, with $7.8 \%$ Ar in air, laminar flow.

\section{Presentation of Results}

The results are presented in the following order. First, the measured surface heat flux and surface temperature data, which provide experimental evidence for the laminar to turbulent transition in the PTF flow, are presented. Second, CFD simulation results assuming laminar and turbulent flow and comparisons with the test data are presented. Finally, both CFD results and experimental data are compared against laminar and turbulent flow theory. These comparisons are done in terms of Stanton number dependence on Reynolds number for laminar and turbulent flows. 
Table 1. Summary of the facility/calibration plate data for the PTF tests

\begin{tabular}{|c|c|c|}
\hline Tests & PTF Cal Run 135 & PTF 141 Run 5 \\
\hline $\begin{array}{c}\text { Condition } 1 \\
p_{\circ}, \mathrm{kPa} \\
I, \mathrm{~A} \\
V, \mathrm{~V} \\
\dot{m}, \mathrm{~g} / \mathrm{s} \\
c_{A r}, \% \\
\bar{h}_{\circ}, \mathrm{MJ} / \mathrm{kg} \\
p_{2}, p_{6}, p_{10}, \mathrm{kPa} \\
Q_{3}, Q_{8}, Q_{13}, Q_{18}, \mathrm{~W} / \mathrm{cm}^{2} \\
T C_{1}, T C_{2}, T C_{3}, T C_{5}, \mathrm{~K} \\
M_{e}, R e_{\theta}, R e_{x}\end{array}$ & $\begin{array}{c}447 \\
2006 \\
3495 \\
167 \\
10.2 \\
20.1 \\
0.79,0.71,0.61 \\
12.8,10.8,9.8,8.9 \\
4.44,259,1.20 \times 10^{5}\end{array}$ & $\begin{array}{c}439 \\
1998 \\
3449 \\
168 \\
10.7 \\
19.2\end{array}$ \\
\hline $\begin{array}{c}\text { Condition 2 } \\
p_{\circ}, \mathrm{kPa} \\
I, \mathrm{~A} \\
V, \mathrm{~V} \\
\dot{m}, \mathrm{~g} / \mathrm{s} \\
c_{A r}, \% \\
\bar{h}_{\circ}, \mathrm{MJ} / \mathrm{kg} \\
p_{2}, p_{6}, p_{10}, \mathrm{kPa} \\
Q_{3}, Q_{8}, Q_{13}, Q_{18}, \mathrm{~W} / \mathrm{cm}^{2} \\
T C_{1}, T C_{2}, T C_{3}, T C_{5}, \mathrm{~K} \\
M_{e}, R e_{\theta}, R e_{x}\end{array}$ & $\begin{array}{c}531 \\
2006 \\
3898 \\
199 \\
9.5 \\
19.9 \\
0.95,0.84,0.70 \\
13.3,11.6,10.5,9.6 \\
4.39,277,1.35 \times 10^{5}\end{array}$ & $\begin{array}{c}521 \\
1997 \\
3855 \\
199 \\
9.5 \\
19.0\end{array}$ \\
\hline $\begin{array}{c}\text { Condition } 3 \\
p_{\circ}, \mathrm{kPa} \\
I, \mathrm{~A} \\
V, \mathrm{~V} \\
\dot{m}, \mathrm{~g} / \mathrm{s} \\
c_{A r}, \% \\
\bar{h}_{\circ}, \mathrm{MJ} / \mathrm{kg} \\
p_{2}, p_{6}, p_{10}, \mathrm{kPa} \\
Q_{3}, Q_{8}, Q_{13}, Q_{18}, \mathrm{~W} / \mathrm{cm}^{2} \\
T C_{1}, T C_{2}, T C_{3}, T C_{5}, \mathrm{~K} \\
M_{e}, R e_{\theta}, R e_{x}\end{array}$ & $\begin{array}{c}614 \\
2006 \\
4295 \\
231 \\
9.1 \\
19.8 \\
1.13,0.99,0.82 \\
15.2,13.5,12.3,11.2 \\
4.35,293,1.49 \times 10^{5}\end{array}$ & $\begin{array}{c}602 \\
1999 \\
4249 \\
231 \\
9.1 \\
18.9\end{array}$ \\
\hline $\begin{array}{c}\text { Condition } 4 \\
p_{\circ}, \mathrm{kPa} \\
I, \mathrm{~A} \\
V, \mathrm{~V} \\
\dot{m}, \mathrm{~g} / \mathrm{s} \\
c_{A r}, \% \\
\bar{h}_{\circ}, \mathrm{MJ} / \mathrm{kg} \\
p_{2}, p_{6}, p_{10}, \mathrm{kPa} \\
Q_{3}, Q_{8}, Q_{13}, Q_{18}, \mathrm{~W} / \mathrm{cm}^{2} \\
T C_{1}, T C_{2}, T C_{3}, T C_{5}, \mathrm{~K} \\
M_{e}, R e_{\theta}, R e_{x}\end{array}$ & $\begin{array}{c}698 \\
2004 \\
4679 \\
263 \\
8.7 \\
19.8 \\
1.31,1.15,0.95 \\
20.0,17.7,16.0,14.6 \\
4.31,308,1.63 \times 10^{5}\end{array}$ & $\begin{array}{c}686 \\
1998 \\
4623 \\
263 \\
8.7 \\
18.9\end{array}$ \\
\hline
\end{tabular}


Table 1. Summary of the facility/calibration plate data for the PTF tests (cont'd)

\begin{tabular}{|c|c|c|}
\hline Tests & PTF Cal Run 135 & PTF 141 Run 5 \\
\hline $\begin{array}{c}\text { Condition } 5 \\
p_{\circ}, \mathrm{kPa} \\
I, \mathrm{~A} \\
V, \mathrm{~V} \\
\dot{m}, \mathrm{~g} / \mathrm{s} \\
c_{A r}, \% \\
\bar{h}_{\circ}, \mathrm{MJ} / \mathrm{kg} \\
p_{2}, p_{6}, p_{10}, \mathrm{kPa} \\
Q_{3}, Q_{8}, Q_{13}, Q_{18}, \mathrm{~W} / \mathrm{cm}^{2} \\
T C_{1}, T C_{2}, T C_{3}, T C_{5}, \mathrm{~K} \\
M_{e}, R e_{\theta}, R e_{x}\end{array}$ & $\begin{array}{c}777 \\
2003 \\
5014 \\
295 \\
8.5 \\
19.4 \\
1.49,1.29,1.07 \\
25.7,22.2,19.8,18.0 \\
4.29,324,1.78 \times 10^{5}\end{array}$ & $\begin{array}{c}764 \\
1996 \\
4959 \\
295 \\
8.5 \\
18.6\end{array}$ \\
\hline $\begin{array}{c}\text { Condition } 6 \\
p_{\circ}, \mathrm{kPa} \\
I, \mathrm{~A} \\
V, \mathrm{~V} \\
\dot{m}, \mathrm{~g} / \mathrm{s} \\
c_{A r}, \% \\
\bar{h}_{\circ}, \mathrm{MJ} / \mathrm{kg} \\
p_{2}, p_{6}, p_{10}, \mathrm{kPa} \\
Q_{3}, Q_{8}, Q_{13}, Q_{18}, \mathrm{~W} / \mathrm{cm}^{2} \\
T C_{1}, T C_{2}, T C_{3}, T C_{5}, \mathrm{~K} \\
M_{e}, R e_{\theta}, R e_{x}\end{array}$ & $\begin{array}{c}860 \\
2003 \\
5349 \\
327 \\
8.3 \\
19.3 \\
1.66,1.44,1.19 \\
29.8,25.5,22.7,20.5 \\
4.26,338,1.91 \times 10^{5}\end{array}$ & $\begin{array}{c}844 \\
1998 \\
5288 \\
327 \\
8.3 \\
18.4\end{array}$ \\
\hline $\begin{array}{c}\text { Condition } 7 \\
p_{\circ}, \mathrm{kPa} \\
I, \mathrm{~A} \\
\mathrm{~V}, \mathrm{~V} \\
\dot{m}, \mathrm{~g} / \mathrm{s} \\
c_{A r}, \% \\
\bar{h}_{\circ}, \mathrm{MJ} / \mathrm{kg} \\
p_{2}, p_{6}, p_{10}, \mathrm{kPa} \\
Q_{3}, Q_{8}, Q_{13}, Q_{18}, \mathrm{~W} / \mathrm{cm}^{2} \\
T C_{1}, T C_{2}, T C_{3}, T C_{5}, \mathrm{~K} \\
M_{e}, R e_{\theta}, R e_{x}\end{array}$ & $\begin{array}{c}939 \\
2003 \\
5666 \\
358 \\
7.8 \\
19.1 \\
1.83,1.58,1.30 \\
32.3,27.5,24.4,21.9 \\
4.24,352,2.05 \times 10^{5}\end{array}$ & $\begin{array}{c}924 \\
1996 \\
4959 \\
295 \\
8.5 \\
18.6\end{array}$ \\
\hline
\end{tabular}

Plate deflection for all cases is $0^{\circ}$.

Bulk enthalpy $\bar{h}_{\circ}$ is determined by the sonic flow method of Winovich. ${ }^{17}$

$M_{e}, R e_{\theta}$, and $R e_{x}$ values are from the laminar CFD simulations at the $Q_{3}$ gage location.

\section{A. Test Data-Experimental Evidence}

The present tests were conducted at a nominal arc current of $2000 \mathrm{~A}$ and varying total mass flow rates from $169 \mathrm{~g} / \mathrm{s}$ to $358 \mathrm{~g} / \mathrm{s}$ (total pressures ranging from $447 \mathrm{kPa}$ to $939 \mathrm{kPa}$ ) at seven different conditions. Keeping the arc current constant yields a relatively narrow range of total enthalpy for these seven conditions but sufficient change in Reynolds number such that transition from laminar to turbulent flow in the PTF is observed. A summary of the test data from the water-cooled calibration plate and the RCG-coated tile plate, including estimated Mach and Reynolds numbers, is given in Table 1. 


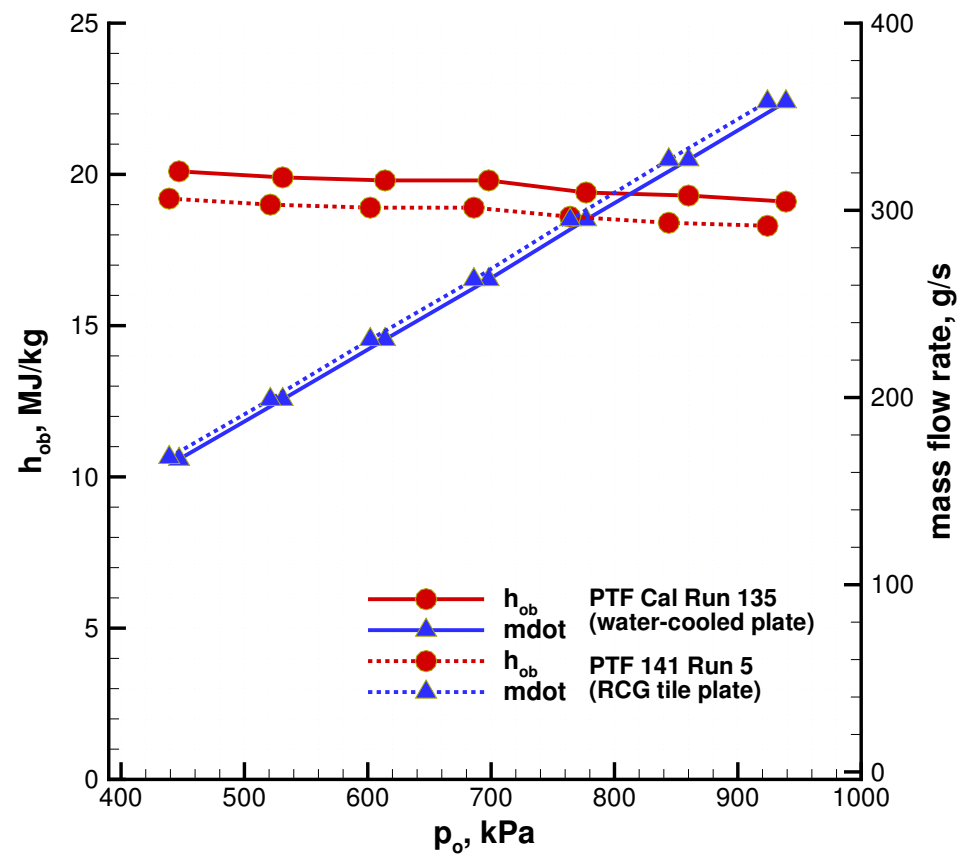

Fig. 4 Variations of mass flow rate and total enthalpy as functions of total pressure for the constant current study $(I=2000$ A $)$.

Figure 4 shows variations of total mass flow rate and estimated total enthalpy as functions of total pressure for the constant current study. The water-cooled calibration plate data were obtained during PTF Cal Run 135, and the RCG-coated tile data were obtained at similar conditions during PTF 141 Run 5. Even though the mass flow rate and arc current were at the same nominal conditions for each condition of both arc-jet runs, for the PTF 141 Run 5 conditions, the total pressure values were $1.6 \%$ $2.0 \%$ lower (resulting in $2.6 \%-4.7 \%$ lower estimated total enthalpy values).

Figure 5 shows variations of selected calorimeter heat flux and surface thermocouple temperatures as functions of total pressure. Calorimeters $Q_{3}$ and $Q_{13}$ are located on the centerline of the water-cooled calibration plate, while calorimeters $Q_{11}$ and $Q_{15}$ are at off-centerline locations (14.6 cm away from the centerline, see Fig. 1b). Surface thermocouples $T C_{1}$ and $T C_{3}$ are located on the centerline of the RCG tile plate, while thermocouples $T C_{7}$ and $T C_{10}$ are symmetrically $12.4 \mathrm{~cm}$ away from the plate centerline (Fig. 2b). All calorimeter heat flux values and thermocouple temperatures are rising with the increasing total pressure, as expected. The $Q_{13}$ heat flux values are lower than for $Q_{3}$. This is because the surface pressure drops along the calibration plate centerline as the flow exiting the nozzle continues to expand (Fig. 3a). The significant rise in $Q_{3}$ and $Q_{13}$ values between condition 3 and condition 4 , which cannot be explained by the incremental increase in the total pressure for laminar flow, indicates a departure from laminar flow and hence possible transition to turbulent flow. Similarly, the centerline surface thermocouples of the RCG tile plate, $T C_{1}$ and $T C_{3}$, show significant increase between condition 3 and condition 4 . It should be noted that the off-centerline calorimeters and thermocouples do not show significant increases between condition 3 and condition 4 . It is plausible that at these locations, departures from laminar flow occur at lower total pressures than those covered in this study. Although the convergence of surface temperatures from all thermocouples shown in Fig. 5 to a single temperature for conditions 5, 6 and 7 is not well understood, it is possible that as the flow transitions to turbulent flow, the heating pattern on the plate becomes more uniform, and the heating increase due to the flow transition overwhelms the heating reduction due to flow expansion after the nozzle exit. The flow over the tile plate appears to transition later than the flow over the water-cooled plate. The fact that calorimeters $Q_{11}$ and $Q_{15}$ and thermocouples $T C_{7}$ and $T C_{10}$ are in agreement with each other indicates that the heating pattern on these test plates is symmetric. Consequently, the PTF flow at 


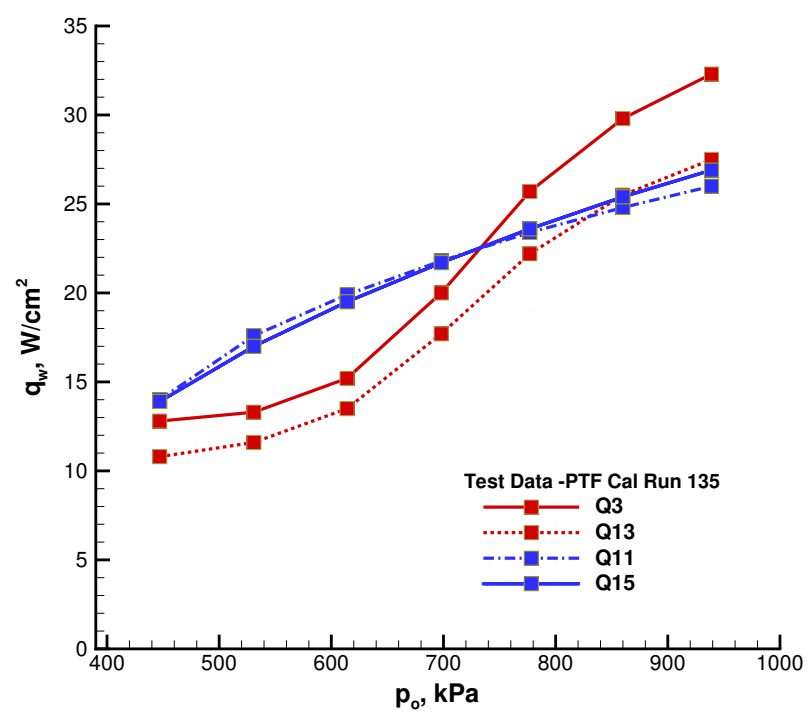

a) water-cooled calibration plate

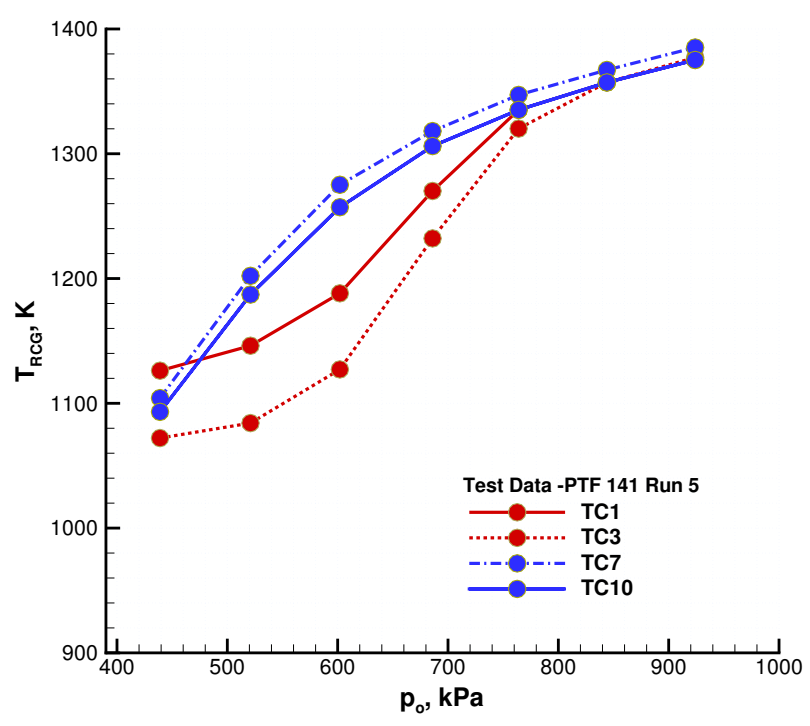

b) RCG tile plate

Fig. 5 Variations of the calorimeter heat flux and surface thermocouple temperatures as functions of total pressure $(I=2000 \mathrm{~A})$.

these conditions is also likely to be symmetric with respect to the $\mathrm{x}-\mathrm{y}$ plane.

During the PTF 141 Run 5, the RCG plate was also viewed with a high-definition (HD) video camera and an infrared (IR) camera from the top. HD video and IR temperature maps of the RCG coated tile plate are provided from the test facility as qualitative data. Figure 6 shows HD photographs and IR temperature images from the PTF 141 Run 5 at two conditions (4 and 7), depicting the change of heating patterns on the tile plate before and after the flow disturbances spread over the tile plate. Note that the flow direction for both HD photographs and IR temperature images is from top to bottom, opposite to the flow direction used in Fig. 1b and Fig. 2b. The digital IR image shows an approximately $25 \mathrm{~cm} \times 25 \mathrm{~cm}$ area on the surface of the RCG tile plate. These temperature maps provide qualitative validation for the surface thermocouple data presented in Fig. 5b.

\section{B. CFD Results and Comparisons with Test Data}

As stated earlier, the test data were obtained at seven nominal mass flow rates at constant current of 2000 A. For the PTF 141 Run 5, when the RCG tile plate was used, the mass flow rate and arc current were at the same nominal conditions of PTF Cal Run 135 but the total pressure and total enthalpy values were approximately $2 \%$ and $5 \%$ lower, respectively. CFD simulations are performed at seven conditions corresponding to PTF Cal Run 135.

Of these seven conditions, for three cases, at total presssures of $447 \mathrm{kPa}, 614 \mathrm{kPa}$ and $939 \mathrm{kPa}$ (condition 1, 3, and 7), the computed surface quantities of the two calibration plates (water-cooled and RCG-coated tile plates) are presented and compared with the measurements in Figs. 7-9.

For the first case at $447 \mathrm{kPa}$, condition 1, the lowest arc-heater pressure case out of the seven cases, contours of the computed surface pressure, heat flux and temperature on one half of the two calibration plates and the corresponding profiles along the plate centerline in the streamwise direction are presented in Fig. 7. Also shown in the contour and line plots of Fig. 7 are the surface pressure, heat flux and thermocouple meausurements. The symbols in the contour plots are the measurements, color coded with the same contour colors. The computed pressure and heating distributions on the test plate are typical of those observed in a semi-free jet expansion. Both pressure and heat flux on the water-cooled plate decrease away from the nozzle exit as the flow exiting the nozzle continues to expand. As expected, the surface temperatures on the RCG plate also decrease away from the nozzle exit. Note that the RCG surface temperatures are calculated using radiative equilibrium boundary condition $(\epsilon=0.89)$. Since the test box pressure is lower than the nozzle exit pressure (under-expanded nozzle flow), the flow continues to expand after exiting the nozzle. The expansion waves emanating from the nozzle exit into the test 

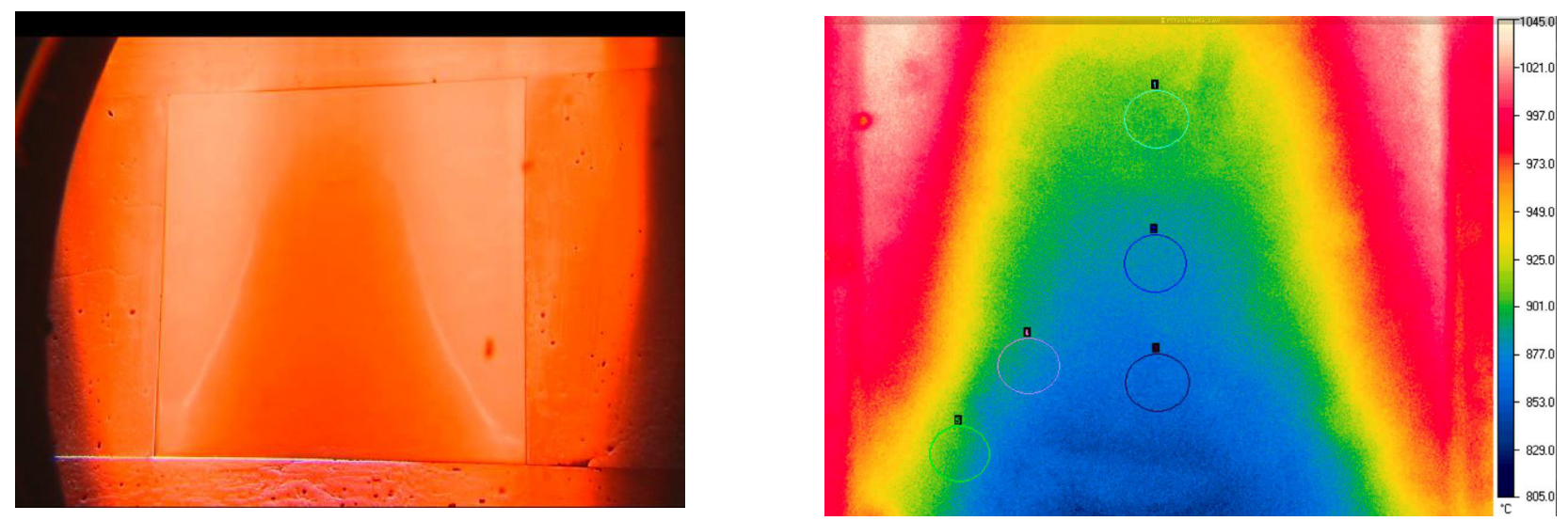

a) condition 4


b) condition 7

Fig. 6 HD camera photographs and infrared temperature maps of the RCG-coated tile plate taken during PTF 141 Run 5, showing the significant change in heating patterns (qualitative data). The flow direction for both pairs of images is from top to bottom.

box interact with the flow over the test plate, thus affecting the distributions of pressure and heat flux on the plate surface. The computations predict that a panel area of approximately $36 \mathrm{~cm} \times 36 \mathrm{~cm}$ $(14 \mathrm{in} \times 14 \mathrm{in})$ is unaffected by the expansion waves. For this case, the computations overall show reasonably good agreement with the surface pressure, heat flux and temperature measurements, which are believed to be accurate to within $\pm 5 \%, \pm 15 \%$, and $\pm 4 \%$, respectively. It should be pointed out that the heat flux agreement at off-centerline locations is not as good as that at the plate centerline; and the measured surface temperatures do not show any significant increase at off-centerline locations, although they are approximately 5-6\% higher than the computations.

For the second case at $614 \mathrm{kPa}$ (one of the intermediate arc-heater pressure cases), contours of the computed surface pressure, heat flux and temperature on one half of the two calibration plates and the plate centerline profiles are shown in Fig. 8. For this case, the computations predict the measured surface pressures well, but they show some differences with respect to the heat flux and temperature measurements, especially at off-centerline locations. The surface temperature measurements, similar to the heat flux measurements, are higher at the off-centerline locations. It is plausible that transition or disturbances to the laminar flow start at off-center locations (e. g., upstream interface between watercooled nozzle wall and conditioning plate).

For the third case at $939 \mathrm{kPa}$ (the highest pressure case out of the seven cases), similar to Figs. 7 and 8, Fig. 9 shows contours of the computed surface pressure, heat flux and temperature on one half of the two calibration plates and the plate centerline profiles. For this case, although the computations 

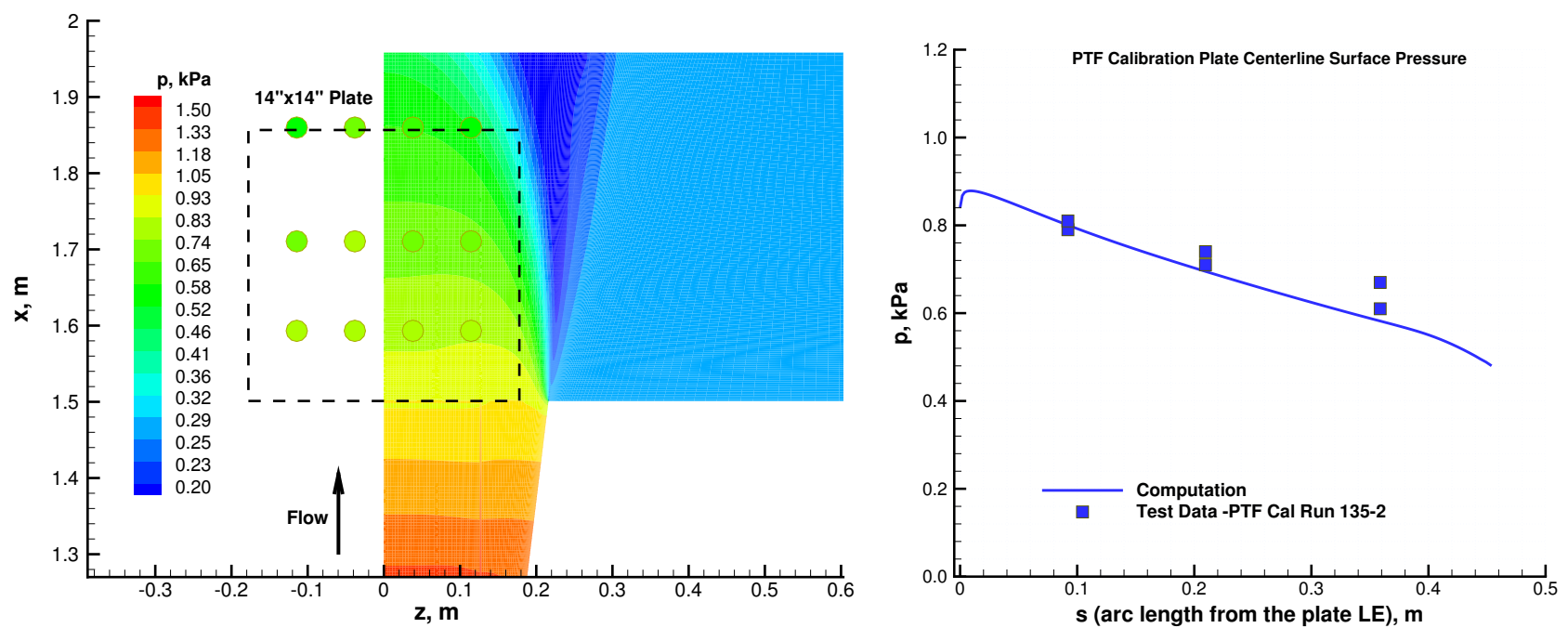

a) pressure


b) water-cooled calibration plate heat flux


c) RCG tile plate temperature

Fig. 7 Computed contours of surface quantities of the PTF calibration plates and their centerline profiles at $0^{\circ}$ plate deflection. Condition 1: $p_{o}=447 \mathrm{kPa}, h_{o}=\bar{h}_{\circ}=20.1 \mathrm{MJ} / \mathrm{kg}$, $\mathrm{p}_{\text {box }}=2$ torr, with $10.2 \%$ Ar in air, laminar flow. 

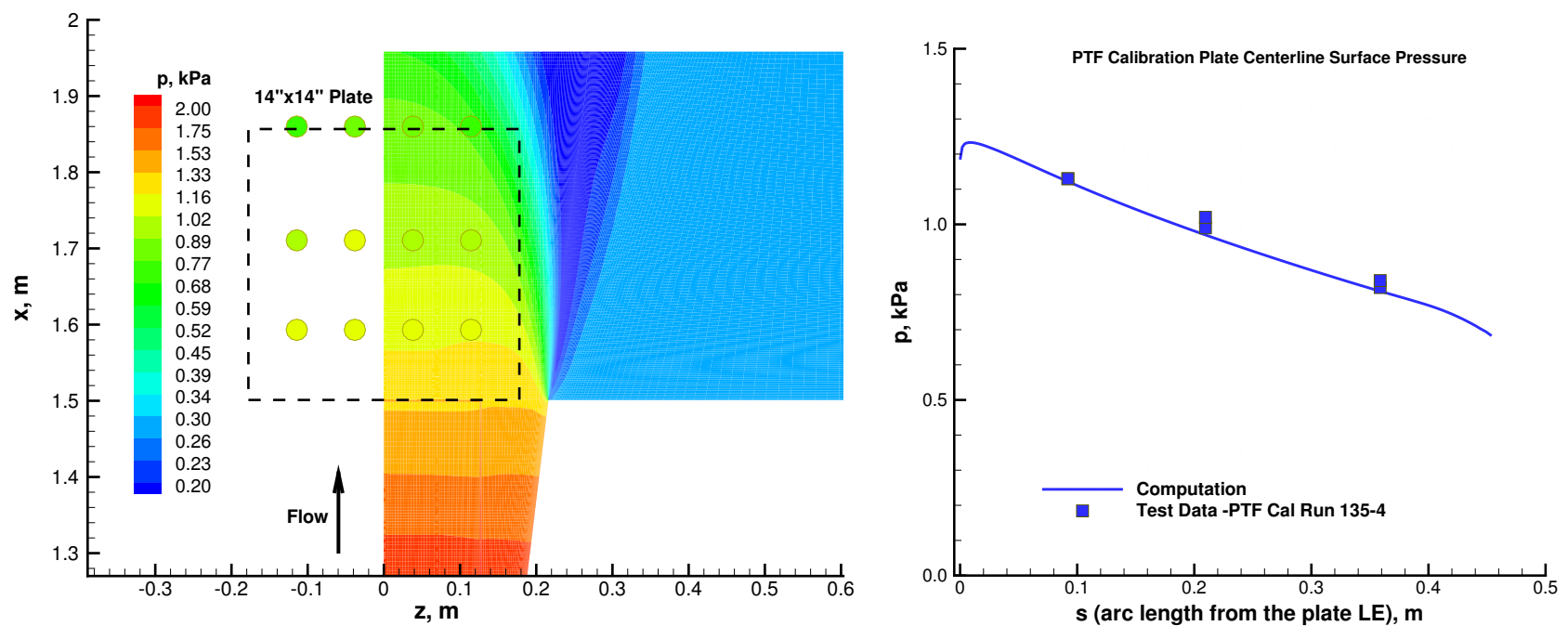

a) pressure


b) water-cooled calibration plate heat flux
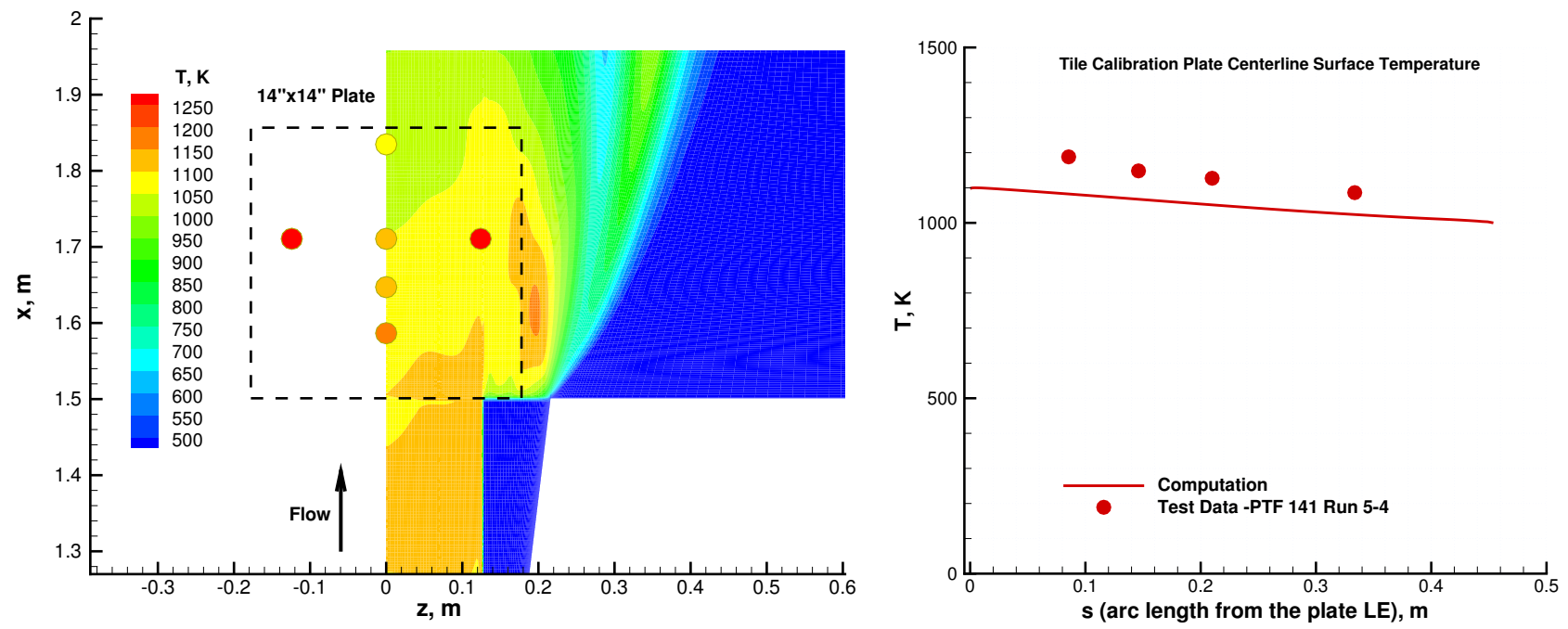

c) RCG tile plate temperature

Fig. 8 Computed contours of surface quantities of the PTF calibration plates and their centerline profiles at $0^{\circ}$ plate deflection. Condition $3: p_{o}=614 \mathrm{kPa}, h_{o}=\bar{h}_{\circ}=19.8 \mathrm{MJ} / \mathrm{kg}$, $\mathrm{p}_{\text {box }}=2$ torr, with $9.1 \%$ Ar in air, laminar flow. 

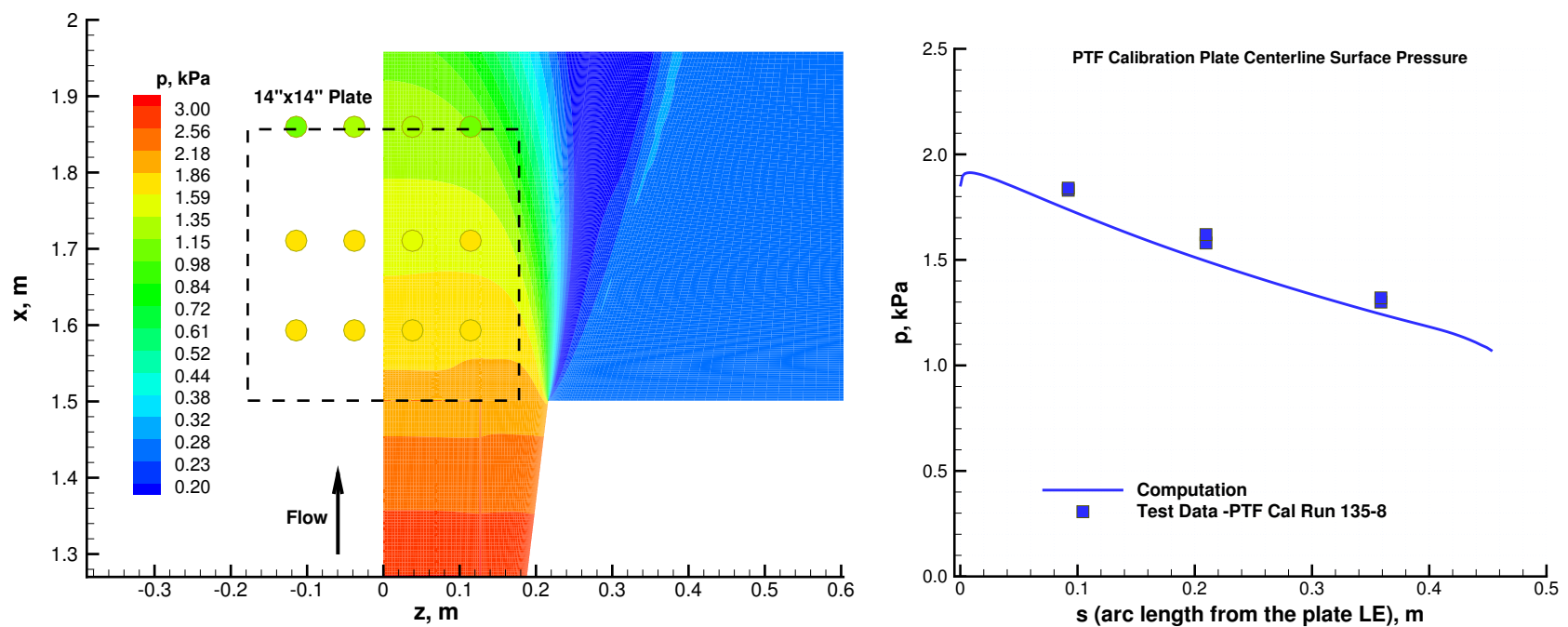

a) pressure
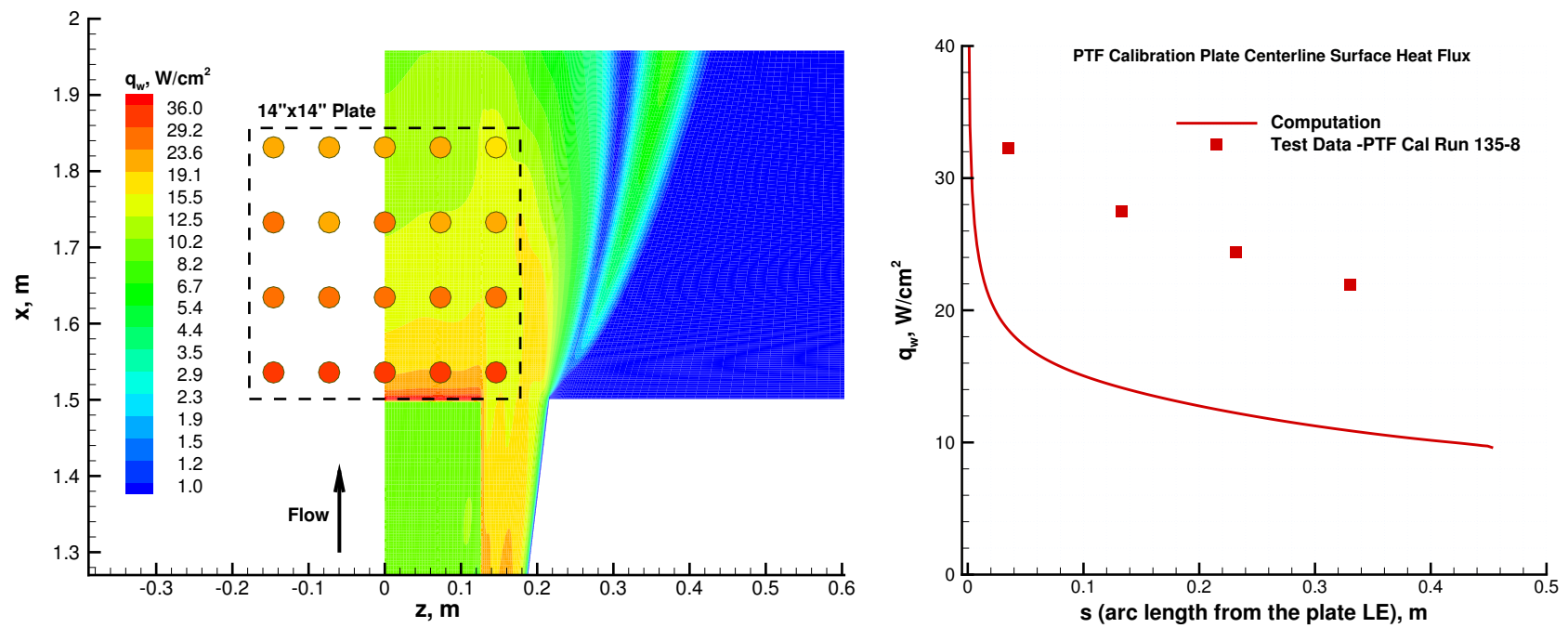

b) water-cooled calibration plate heat flux


c) RCG tile plate temperature

Fig. 9 Computed contours of surface quantities of the PTF calibration plates and their centerline profiles at $0^{\circ}$ plate deflection. Condition $7: p_{o}=939 \mathrm{kPa}, h_{o}=\bar{h}_{\circ}=19.1 \mathrm{MJ} / \mathrm{kg}$, $\mathrm{p}_{\text {box }}=2$ torr, with $\mathbf{7 . 8 \%}$ Ar in air, laminar flow. 



a) pressure
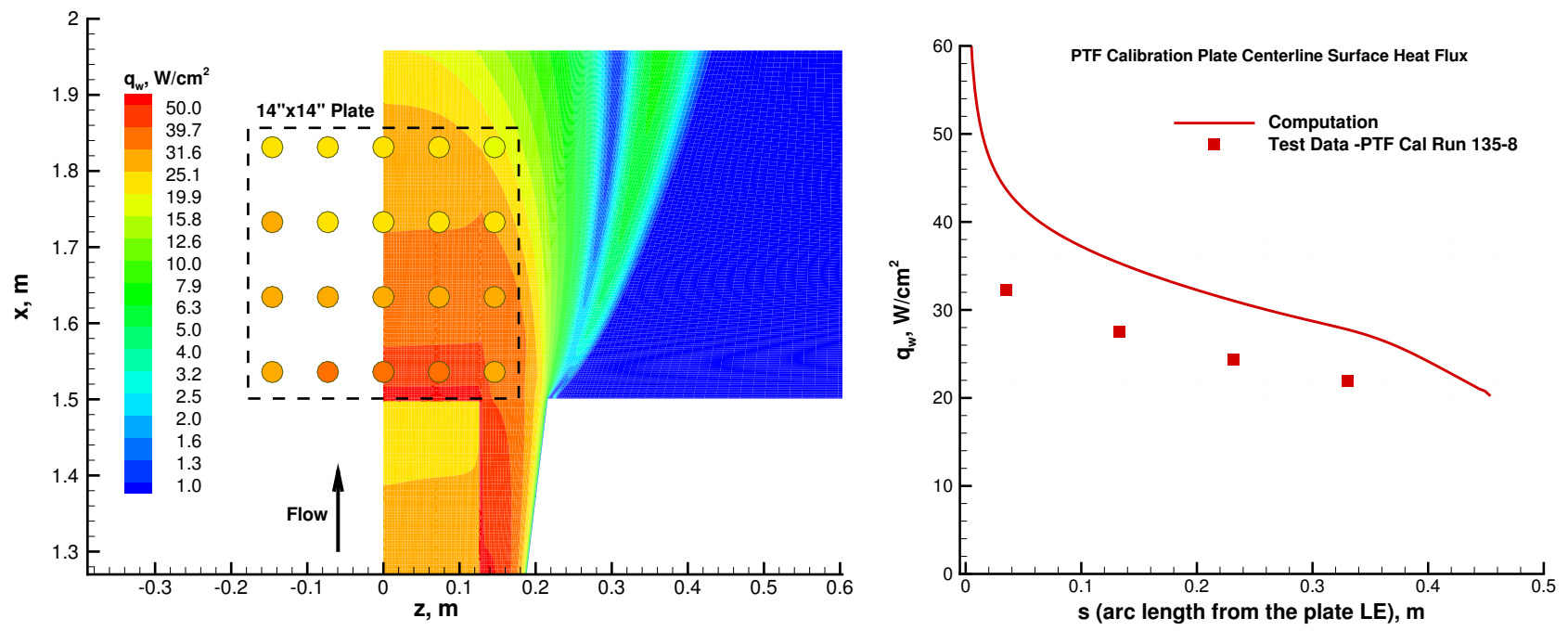

b) water-cooled calibration plate heat flux


c) RCG tile plate temperature

Fig. 10 Computed contours of surface quantities of the PTF calibration plates and their centerline profiles at $0^{\circ}$ plate deflection. Condition $7: p_{o}=939 \mathrm{kPa}, h_{o}=\bar{h}_{\circ}=19.1 \mathrm{MJ} / \mathrm{kg}$, $\mathrm{p}_{\text {box }}=2$ torr, with $7.8 \%$ Ar in air, turbulent flow (SST 2003 model).

American Institute of Aeronautics and Astronautics 


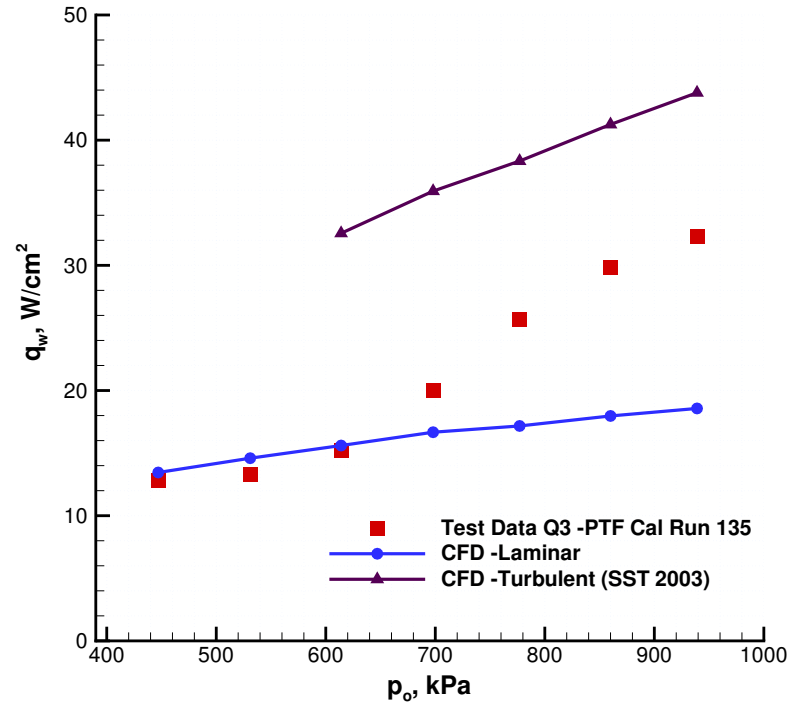

a) cold-wall heat flux

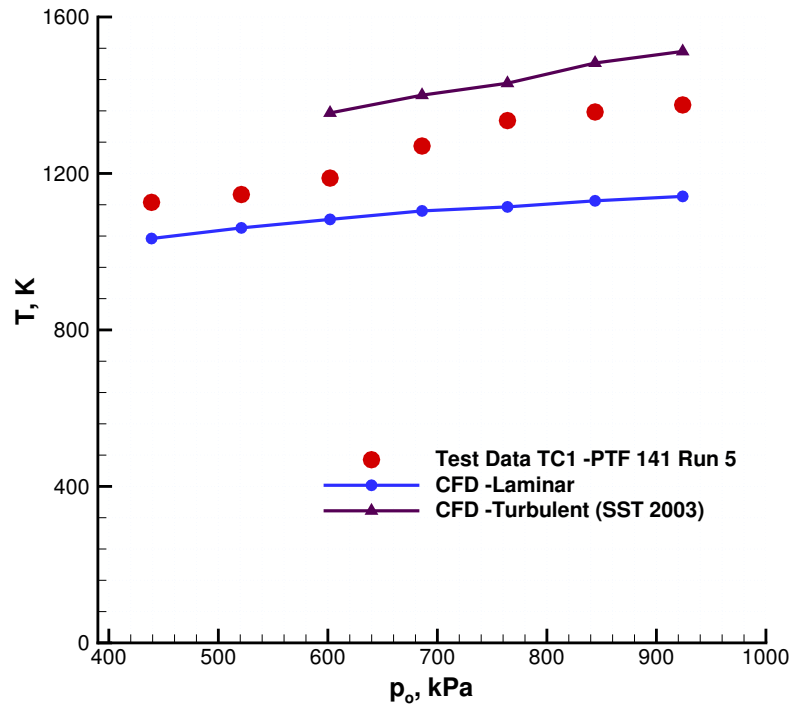

b) RCG tile temperature

Fig. 11 Variations of the water-cooled calibration plate heat flux data at the $Q_{3}$ gage location and surface temperature of the RCG tile plate at the $T C_{1}$ location with total pressure, and corresponding laminar and turbulent computations.

show reasonable agreement with the measured surface pressures, they obviously do not show good agreement with the surface heat flux and temperature measurements, which are both significantly underpredicted. The underprediction of the measured surface pressures, though not as pronounced, is likely due to the displacement effect of the thicker transitional or turbulent boundary layer in the nozzle. This disagreement of the laminar CFD results with the test data at this condition is consistent with the transitional flow argument presented in the previous section.

Up to this point, only laminar CFD simulation results are presented. Turbulent CFD simulations are also performed using the SST 2003 turbulence model of Menter. ${ }^{14}$ Here, only the turbulent simulation results for condition 7, the highest total pressure case, are presented. In Fig. 10, contour and line plots of the computed surface pressure and heat flux on the water-cooled plate and computed temperature on the RCG tile plate are presented with the corresponding test data. The surface pressure, heat flux, and temperature are overpredicted by the turbulent simulations. The fact that computed pressures for turbulent flow are higher than the test data, while computed pressures are slightly lower than the data for laminar flow (in Fig. 9a), implies that transition to turbulence may not have taken place as early as the turbulent CFD computations indicate. The difference in computed surface pressures for laminar and turbulent flows is due to the the displacement effect of the laminar and turbulent boundary layers in the nozzle. The present turbulent CFD simulations assume that the flow at the nozzle inlet is turbulent. Although turbulent simulations were performed in Ref. 1 such that the flow is transitioned to turbulence at certain axial nozzle location in order to keep the agreement with the measured surface pressures intact, they are not attempted here. These fully-turbulent nozzle simulation results are considered as a limiting case. It should be noted that the measured spanwise heating distributions over the plates with respect to the z-direction show relatively less variation for this condition than the other conditions. The corresponding computed results for the surface heat flux and temperature also show much less variation than those of the laminar flow in Fig. 9. Although the calibration plate heat flux and tile plate temperatures are overpredicted, the disagreement is much less than for the laminar computations presented in Figs. 9b and 9c.

The water-cooled calibration plate heat flux data obtained from the $Q_{3}$ gage, RCG tile surface temperature data from the $T C_{1}$ thermocouple, and corresponding laminar and turbulent CFD results at the $Q_{3}$ and $T C_{1}$ locations are presented in Fig. 11. Both heat flux gage $Q_{3}$ and thermocouple $T C_{1}$ are located along the plate centerline, approximately $3.49 \mathrm{~cm}$ and $8.55 \mathrm{~cm}$ downstream of the nozzle exit, 
respectively (Fig. 1b and Fig. 2b). In Fig. 11a, computed and measured heat fluxes at the $Q_{3}$ location are plotted as functions of total pressure. As expected, the computed and measured heat fluxes increase with increasing total pressure. Considering the relatively small variations in the total enthalpy range (19.1-20.1 MJ $/ \mathrm{kg}$ ) for these cases, the significant rise in the measured heat flux at total pressures between $600 \mathrm{kPa}$ and $700 \mathrm{kPa}$ cannot be explained by the laminar flow calculations. In Fig. 11b, computed and measured surface temperatures at the $T C_{1}$ location are plotted. Although the laminar CFD simulations underpredict the tile surface temperature at this thermocouple location by about $7-8 \%$ for the first three cases, the discrepancy increases significantly at the higher pressures, to as much as $17 \%$.

\section{Nondimensional Parameters and Comparisons with Flat Plate Theory}

In this section, the CFD results and data are presented with nondimensional parameters, and their functional forms are compared against those of the flat plate boundary layer theory.

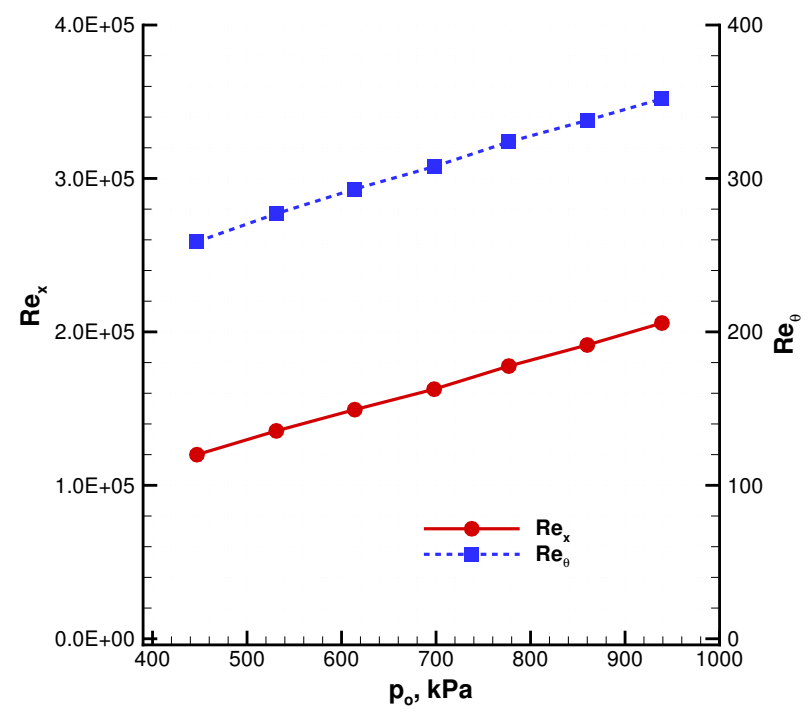

a) Reynolds numbers

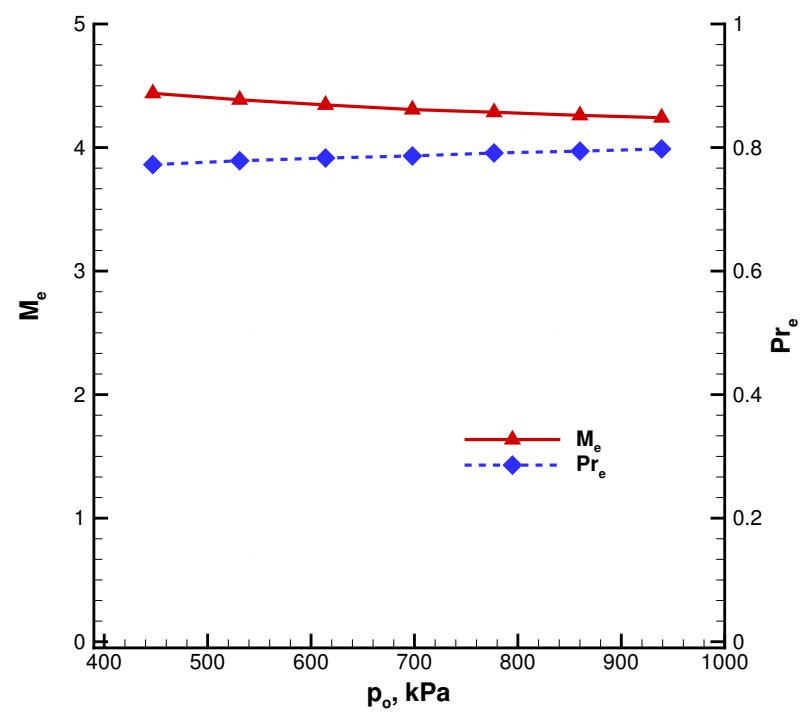

b) Mach and Prandtl numbers

Fig. 12 Variations of the computed boundary layer edge flow parameters with total pressure: CFD results for laminar flow at the $Q_{3}$ gage location of the water-cooled calibration plate.

In Fig. 12, for the seven cases, variations of boundary layer edge flow parameters with total pressure at the $Q_{3}$ gage location of the water-cooled calibration plate are presented. The boundary layer edge parameters are obtained from the laminar CFD simulations of the seven cases. Note that the edge of the boundary layer is determined from the total enthalpy profile normal to the wall as the location at which $h_{\mathrm{oe}}=0.995 h_{\mathrm{ocl}}$. For the constant current study conditions, both $R e_{x}$ and $R e_{\theta}$ linearly increase with the total pressure. Note that $R e_{x}$ is based on the distance from the throat. This choice of the length scale is made somewhat arbitrarily. (Although the origin of the boundary layer is further upstream of the throat, the boundary layer thickness at the throat is expected to be small in comparison with the boundary layer thickness over the test plate.) Also, it should be noted that either $R e_{x}$ or $R e_{\theta}$ can be used as a correlation parameter. As expected, for the seven conditions, the variations of $M_{e}$ and $P r_{e}$ with $p_{o}$ are relatively small: $M_{e}$ ranges from 4.439 to 4.242 , and $\operatorname{Pr}_{e}$ ranges from 0.772 to 0.798 .

Although the flow over a plate in the PTF semi-free jet test configuration is quite different from a flow over a flat plate, most importantly in terms of development of the boundary layer in the nozzle and existing pressure gradients over the PTF nozzle and plate, it is still informative to look at Stanton number dependence on Reynolds number for laminar and turbulent flows over a flat plate. Differences in transport mechanisms of laminar and turbulent boundary layer flows result in different heat transfer correlations. In other words, nondimensional heat transfer coefficient, Stanton number, has different 
functional dependence on Reynolds number for laminar and turbulent flows. These functional forms based on self-similar solutions of the boundary layer equations over a flat plate are given in classical heat transfer books, e.g., Dorrance ${ }^{18}$ or Kays and Crawford. ${ }^{19}$ For uniform incompressible flow over a semi-infinite plate, Kays and Crawford give the following relations, in their simplest forms,

$$
\begin{gathered}
S t=0.332 \operatorname{Re}_{x}^{-1 / 2} \operatorname{Pr}^{-2 / 3} \quad \text { (laminar flow) } \\
S t=0.0287 \operatorname{Re}_{x}^{-0.2} \operatorname{Pr}^{-0.4} \quad \text { (turbulent flow) }
\end{gathered}
$$

In a compressible reacting boundary layer flow, Stanton number takes similar functional forms ${ }^{18,19}$

$$
\begin{array}{ll}
S t & =C_{1} \operatorname{Re}_{x}^{-1 / 2} \operatorname{Pr}^{-2 / 3} \quad \text { (laminar flow) } \\
S t & =C_{2} \operatorname{Re}_{x}^{-0.2} \operatorname{Pr}^{-0.4} \quad \text { (turbulent flow) }
\end{array}
$$

where $C_{1}$ and $C_{2}$ depend on a number of flow parameters including Mach number, total enthalpy, wall temperature (or wall enthalpy), specific heat, dissociation level, pressure gradient, state of the boundary layer (equilibrium, frozen, nonequlibrium).



Fig. 13 Variation of Stanton number as a function of Reynolds number for the PTF watercooled calibration plate heat flux data at the $Q_{3}$ gage location and corresponding CFD computations.

In Fig. 13, Stanton numbers computed from the CFD results and test data are plotted against the computed Reynolds numbers. The experimental Stanton and Reynolds numbers are computed based on the CFD-predicted laminar boundary layer edge quantities. Assuming that the functional forms in Eqs. (3) and (4) are applicable for the flow over the PTF plates, theoretical laminar and turbulent lines are also plotted in Fig. 13. The objective here is not to develop a simplified Stanton number correlation for the CFD results and/or test data. Instead, it is intended to show that the computed laminar and turbulent CFD results follow theoretical functional forms, and the nondimensional PTF data also follow the laminar line at lower Reynolds numbers (at the lower mass flow rates). At higher Reynolds numbers 
the PTF data start to diverge from that theoretical laminar line. This plot clearly shows that at Reynolds numbers greater than $1.6 \times 10^{5}$, corresponding to $263 \mathrm{~g} / \mathrm{s}$ mass flow rate at arc-current of $2000 \mathrm{~A}$, the measurements diverge from the laminar CFD results and theoretical laminar line.

\section{Uncertainties of Computations and Measurements}

The three-dimensional CFD computations of the nozzle/test-box/model flowfield were performed using multi-block grids. For the PTF plate simulations, a 14-block grid was used with $5.62 \times 10^{6}$ cells. The number of cells from the nozzle inlet to the test plate exit was 540, with 120 cells normal to the wall along the nozzle and 180 over the test article. Based on the authors' judgement, and a limited number of grid refinement studies, the authors believe that the grid quality issues of the computations were adequately addressed.

However, CFD computations of arc-jet flows, as for hypersonic flight simulations, include uncertainties in many of the model input parameters. It is not possible at this time to do a complete uncertainty analysis of computed results for all of the simulation input parameters. In the authors' opinion, the most important input parameter of the arc-jet test flow is the total enthalpy (and its distribution) at the nozzle inlet. For the semi-free jet test configuration in the PTF, the computed test plate surface quantities are found to be much more sensitive to the bulk enthalpy than the centerline total enthalpy. This is based on the study performed in Ref. 1, in which simulations were performed with varying degrees of nonuniformity specified in inlet total enthalpy profile, keeping the bulk enthalpy, mass flow rate, pressure, and total pressure constant at the inlet. It was found that although the flowfield chemistry could be altered significantly with a nonuniform total enthalpy profile at the nozzle inlet, any effect of this nonuniform profile on the computed test plate surface quantities was secondary. The bulk enthalpy in the PTF is not a measured parameter; it is deduced from the measured arc-heater pressure and mass flow rate. The bulk enthalpy estimate is believed to be accurate to within $\pm 10-15 \%$.

For the PTF calibration and tile plate simulations, the estimated uncertainty in the laminar heat flux predictions is expected to be as much as $\pm 20 \%$, considering the uncertainty in the bulk enthalpy input and other modeling input parameters. For the water-cooled calibration plate simulations, since fully-catalytic cold-wall heat flux predictions are performed, effects of model input parameters, such as chemical reaction rates, surface catalysis, diffusion model, etc., on the computed heat flux values are expected to be secondary. On the other hand, for the RCG tile plate simulations (radiative equilibrium heat flux calculations with RCG surface catalysis), the effects of a partially catalytic surface, chemical reaction rates, surface catalysis, diffusion model, etc., on the computed heat flux values are expected to be more important but cannot be assessed at this time. Although sensitivity and uncertainty of the computed heat flux for the tile plate to modeling parameters is expected to be more than for the watercooled plate, the main contributor to overall uncertainty in heat flux computation is still expected to be the uncertainty in the bulk enthalpy. In heat flux predictions, the turbulent CFD flow simulations bring larger uncertainties than the laminar CFD simulations, and these cannot be assessed without further tests and comparisons.

A complete uncertainty analysis of the calibration and tile plate measurements is also not available. However, based on empirical evidence (historical Ames arc-jet data), the heat flux measurements are believed to be accurate to within $\pm 15 \%$ and the pressure measurements to within $\pm 5 \%$. The thermocouple devices are estimated to be accurate to within $\pm 1-2 \%$; if the measurement errors related to the thermocouple installations are included, they could be as much as $\pm 4 \%$. The surface temperature measurements from the infrared camera were provided as qualitative measurements from the facility, and they are currently regarded as such.

\section{Summary and Concluding Remarks}

This paper is intended to provide experimental evidence and supporting computational analysis to confirm the laminar to turbulent flow transition in the NASA Ames 20-MW Panel Test Facility flow.

The arc-jet test data that included measurements of surface pressure and heat flux on a watercooled calibration plate and surface temperature measurements of RCG-coated tile plate were obtained at seven arc-heater conditions. For these seven conditions, the arc-heater current was kept constant, and 
the arc-heater pressure (or mass flow rate) was systematically increased. In doing so, the total enthalpy of the flow varied by only $5 \%$ but the freestream Reynolds numbers of the flow over the plates were increased by a factor of 1.7 , and as a result, laminar to turbulent flow transition was observed.

The analysis comprises both laminar and turbulent simulations of the nonequilibrium flowfield in the facility nozzle and the test box, and comparisons with the experimental measurements. Computational simulations are used to define arc-jet test environments consistent with the facility and calibration measurements. Comparisons of computed and measured surface heat fluxes (and temperatures), as well as the accompanying Stanton number analysis, confirm that the boundary layer in the PTF becomes transitional at certain arc-heater conditions.

CFD computations of arc-jet flows as well as hypersonic flight include uncertainties in many of the model input parameters. In order to reduce these uncertainties and increase the confidence level in predictions, validation of the models against experiments and test data are necessary. For better understanding of the PTF test environment, future work should be directed to determine boundaries of laminar and transitional flow in the PTF facility operating envelope.

\section{Acknowledgments}

Special thanks are due to Kristina Skokova and other members of the Orion TPS Arc-Jet Testing Group involved in the PTF compression-pad test program (PTF Cal Run 135 and 136, and PTF 141) for including the facility calibration runs at constant current. The authors would also like to thank the Thermophysics Facilities Branch members for providing information on the arc-jet facilities and conducting the arc-jet tests, particularly Frank Hui, Imelda Terrazas-Salinas, and John Balboni. This work was funded by the NASA Orion TPS Insight/Oversight Project. The arc-jet operational capability at Ames is also supported by NASA-SCAP. The support from the NASA Ames Entry Systems and Technology Division, through contract NNA10DE12C to ERC, Inc., is gratefully acknowledged.

\section{References}

1 Gökçen, T., Alunni, A. I., and Skokova, K. A., "Computational Simulations of Panel Test Facility Flow: Compression-Pad Arc-Jet Tests," AIAA Paper 2011-3635, June 2011.

2 Love, W. L., "Assessment of Turbulent Flow Conditions in the Ames 20 MW Semi-Elliptic Facility," Memorandum to Johnson Space Center, Oct. 1980.

3 Stewart, D. A., Rakich, J. V., and Lanfranco, M. J., "Catalytic Surface Effects Experiment on Space Shuttle," AIAA Paper 81-0143, June 1981.

4 Loomis, M. P., and Palmer, G., "Pre-Flight CFD Analysis of Arc Jet and Flight Environments for the SHARP-B2 Flight Experiment," AIAA Paper 2001-0982, Jan. 2001.

5 Peterson, A. B., Nichols, F., Mifsud, B., and Love, W., "Arc Jet Testing in NASA Ames Research Center Thermophysics Facilities," AIAA Paper 92-5041, Dec. 1992.

6 Terrazas-Salinas, I., and Cornelison, C., "Test Planning Guide for TSF Facilities," Thermophysics Facilities Branch, Space Technology Division, NASA Ames Research Center, Rev. C, April 2009.

7 "Thermophysics Facilities Branch Fact Sheet," Thermophysics Facilities Branch, Space Technology Division, NASA Ames Research Center, Jan. 2005.

8 Balboni, J. A., Gökçen, T., Hui, F. C. L., Taunk, J., Noyes, E., and Schickele, D., "Calibration of the Truncated Panel Test Arc-Jet Facility," AIAA Paper 2009-4090, June 2009.

9 Wright, M. J., Candler, G. V., and Bose, D., "Data-Parallel Line Relaxation Method for the NavierStokes Equations," AIAA Journal, Vol. 36, No. 9, Sept. 1998, pp. 1603-1609.

10 Wright, M. J., "Data-Parallel Line Relaxation (DPLR) Code, Version 4.02," Private Communication, April 2010.

11 Park, C., Nonequilibrium Hypersonic Aerothermodynamics, John Wiley \& Sons, Inc., New York, 1990, Chap. 4. 
12 Park, C., "Assessment of a Two-Temperature Kinetic Model for Dissociating and Weakly Ionizing Nitrogen," Journal of Thermophysics and Heat Transfer, Vol. 2, No. 1, 1988, pp. 8-16.

13 Stewart, D. A., "Surface Catalysis and Characterization of Proposed Candidate TPS for Access-toSpace Vehicles," NASA TM 112206, July 1997.

14 Menter, F. R., "Two-Equation Eddy-Viscosity Turbulence Models for Engineering Applications," AIAA Journal, Vol. 32, No. 8, Aug. 1994, pp. 1598-1605.

15 Brown, J. L., "Turbulence Model Validation for Hypersonic Flows," AIAA Paper 2002-3308, June 2002.

16 "Gridgen, Version 15.16," Pointwise, Inc., Fort Worth, TX.

17 Winovich, W., "On the Equilibrium Sonic-Flow Method for Evaluating Electric-Arc Air-Heater Performance," NASA TN-D-2132, March 1964.

18 Dorrance, W. H., Viscous Hypersonic Flow, McGraw-Hill Book Company, Inc., New York, 1962, Chap. 4 and Chap. 7.

19 Kays, W. M., and Crawford, M. E., Convective Heat and Mass Transfer, Second Edition, McGrawHill Book Company, Inc., New York, 1980, Chap. 9 and Chap. 12. 